\title{
Por uma Saúde e uma Psicologia Equitativa e Interseccional
}

For Equitable and Intersectional Health and Psychology

Por una Salud y una Psicología Equitativas e Interseccionales

Esmael Alves de Oliveira

Universidade Federal da Grande Dourados (UFGD), Dourados, MS, Brasil

\begin{abstract}
Resumo

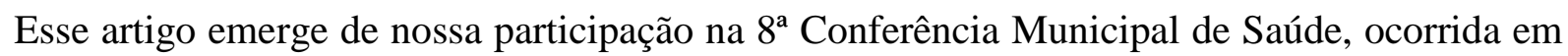
Dourados (MS) em 2019, uma das etapas que antecederam as conferências em nível estadual (em sua $9^{a}$ edição) e nacional (em sua $16^{a}$ edição). As conferências, em todas as suas instâncias, são importantes espaços de participação cidadã e, portanto, de controle social. À luz da perspectiva interseccional, tomamos esse evento como disparador para pensarmos a importância do Sistema Único de Saúde (SUS) e alguns de seus dilemas em torno da noção de equidade, as políticas de saúde em relação à saúde da população LGBTQIA+ e, por fim, os desafios impostos pelo cenário pandêmico às minorias sexuais e de gênero e as implicações disso para a práxis da Psicologia.
\end{abstract}

Palavras-chave: Psicologia; SUS; Equidade; Interseccionalidades.

\begin{abstract}
This article emerges from our participation in the 8th Municipal Health Conference, held in Dourados (MS) in 2019, one of the stages that preceded the conferences at the state level (in its 9th edition) and national level (in its 16th edition). Conferences, in all their instances, are important spaces for citizen participation and, therefore, for social control. In light of the intersectional perspective, we take this event as a trigger to think about the importance of the Unified Health System (SUS) and some of its dilemmas around the notion of equity, health policies in relation to the health of the LGBTQIA+ population, and finally, the challenges posed by the pandemic scenario to sexual and gender minorities and the implications of this for the praxis of Psychology.
\end{abstract}

Keywords: Psychology; SUS; Equity; Intersectionality.

\section{Resumen}

Este artículo surge de nuestra participación en la VIII Jornada Municipal de Salud, celebrada en Dourados (MS) en 2019, una de las etapas que precedieron a las conferencias a nivel estatal (en su novena edición) y nacional (en su 16a edición). Las conferencias, en todas sus instancias, son espacios importantes de participación ciudadana y, por tanto, de control social. A la luz de la perspectiva interseccional, tomamos este evento como un detonante para reflexionar sobre la importancia del Sistema Único de Salud (SUS) y algunos de sus dilemas en torno a la noción de equidad, políticas de salud en relación a la salud de la población 
LGBTQIA +, y finalmente, los desafíos que plantea el escenario pandémico a las minorías sexuales y de género y las implicaciones que esto tiene para la praxis de la Psicología.

Palabras clave: Psicología; SUS; Equidad; Interseccionalidad.

\section{Introdução}

Esse artigo emerge de nossa participação na $8^{\mathrm{a}}$ Conferência Municipal de Saúde, ocorrida em Dourados (MS) em 2019, uma das etapas que antecederam as Conferências em nível estadual (em sua $9^{\mathrm{a}}$ edição) e nacional (em sua $16^{\text {a }}$ edição). As Conferências, em todas as suas instâncias, são importantes espaços de participação cidadã e, portanto, de controle social. Tomamos esse evento como disparador para pensarmos a importância do Sistema Único de Saúde (SUS) e alguns de seus dilemas em torno da noção de equidade, as políticas de saúde em relação à saúde da população LGBTQIA+ e, por fim, os desafios impostos pelo cenário pandêmico às minorias sexuais e de gênero e as implicações disso para a práxis da Psicologia.

No dicionário, o termo equidade, um dos princípios do SUS, é definido como a "disposição de reconhecer igualmente o direito de cada um" (Ferreira, 2001, p. 276). O ABC do SUS o entende como a ação de "assegurar ações e serviços de todos os níveis de acordo com a complexidade que cada caso requeira, more o cidadão onde morar, sem privilégios e sem barreiras. Todo cidadão é igual perante o SUS e será atendido conforme suas necessidades até o limite do que o sistema puder oferecer para todos" (Brasil, 1990a, p. 5. Grifo nosso).

Enquanto um dos princípios do SUS, juntamente com universalidade e integralidade, a equidade preconiza que nossas diferenças precisam ser reconhecidas pelas/nas políticas de Estado a partir de um pressuposto de cidadania socialmente compartilhada. O SUS emerge na constituição cidadã de 1988 e se consolida ao longo da década de 1990, fruto de intensas mobilizações de movimentos sociais e sanitaristas, que entendem que saúde é um direito de todos os cidadãos e cidadãs brasileiros/as. Contudo, a cidadania no Brasil - um país com desigualdades históricas e racismo estrutural - é uma condição a ser constantemente conquistada e reafirmada, haja vista os inúmeros dados de organizações governamentais e não 
governamentais, que apontam que na linha de frente da falta de acessos (p. e. saúde, saneamento, educação), de condições de vida precárias (p. e. sem trabalho e sem moradias dignas) e processos sociais de exclusão (p. e. encarceramento em massa), encontram-se justamente pessoas marcadas por gênero, raça e classe. Afinal, como nos diz Schwarcz:

Raça, gênero, sexo, geração, classe, região são, assim, categorias classificatórias compreendidas como construções particulares (e referidas a determinados contextos específicos), locais, internacionais, históricas e culturais. Elas fazem parte das representações sociais das nossas mitologias, mas também possuem grande impacto no mundo real, uma vez que permitem a produção de identidades coletivas e também de hierarquias, bem como toda sorte de discriminações sociais. Reguladas a partir de convenções e normas, elas acabam fazendo sentido também na interconexão que estabelecem entre si, mesmo que um termo não se reduza obrigatoriamente a outro (2019, p. 16).
A partir disso é que reconhecemos a importância da existência de uma série de mobilizações no interior do campo da saúde no Brasil, principalmente advindas de demandas apresentadas por movimentos sociais, a fim de que sejam garantidas tanto as condições de acesso universal à saúde quanto o atendimento de demandas específicas de sujeitos e coletivos identitariamente diferenciados. Afinal, "o que se coloca em evidência é o fato de que grupos sociais distintos, como negras, índias, mulheres, crianças, idosas e LGBTQIA+, podem ter necessidades de saúde diferenciadas, implicando demandas por ações governamentais também diferenciadas" (Mello et al., 2011, p. 12).

Mas em que medida essas demandas específicas são reconhecidas pelas escalas macro e micro que constituem as políticas públicas de saúde? É o que objetivamos pensar a partir de três cenários distintos: uma conferência municipal de saúde, o estado da arte sobre saúde da população LGBTQIA+ e, por fim, o cenário político-pandêmico em vigência no Brasil e seus impactos em segmentos sociais minoritários.

Nessa análise, três pressupostos são fundamentais: 1) a importância de uma noção ampliada de saúde, 2) os impactos dos determinantes sociais na saúde da 
população, e 3) os marcadores sociais de diferenças nas políticas de saúde e em nossas análises.

Com relação ao primeiro pressuposto, se a “(...) categoria saúde, entendida como uma construção histórica, social e cultural, (...) não se restringe a um marco biologizante" (Mello et al., 2011, p. 11), importa reiterar que as concepções de corpo, saúde, doença, vida, só podem ser bem compreendidas se, além de referenciais epidemiológicos, considerarem-se também dimensões sociais, econômicas, existenciais, cosmológicas, éticas e políticas. Assim, uma concepção de saúde restrita às dimensões orgânico-funcional-individual, preocupada apenas com sintomatologia, tende a permanecer cega aos distintos processos de significação sobre o corpo e o adoecer. Quanto a isso, Duarte, já na década de 1980, em seu trabalho junto a trabalhadores pertencentes a camadas populares, destacava como entre esse segmento o adoecer não estava relacionado a uma sintomatologia orgânico-funcional, mas a uma indisposição para o desenvolvimento das atividades da vida diária (Duarte, 1988). O mesmo se pode perceber na pesquisa realizada por Silveira (2000) junto a mulheres moradoras do Campeche, sul da ilha de Santa Catarina, que apresentavam "crises dos nervosos". Pertencentes às camadas populares, inseridas em contextos marcados por relações de gênero assimétricas, baseadas no modelo patriarcal, as experiências das mulheres revelam os meandros das significações sociais atribuídas a fenômenos tipicamente enquadrados no domínio/propriedade biomédico. Após percorrer as histórias pessoais e os dramas cotidianos, a autora evidencia que a experiência de adoecimento se constitui como uma linguagem cheia de significados. Nas palavras de Silveira (2000), o nervo cala, o nervo fala. Não se trata, portanto, da mera somatização de “problemas psicológicos”. A experiência de adoecimento está atrelada a fenômenos que excedem o orgânico-fisiológico.

No que se refere ao segundo pressuposto - determinantes sociais - , se a lei de criação do SUS (Lei n. 8.080/1990) já preconizava os impactos dos fatores determinantes e condicionantes em saúde ${ }^{1}$, Barata (2009) nos chama a atenção para a indissociabilidade entre condições sociais e saúde. De acordo com a pesquisadora, é preciso considerar que não apenas "saúde é um produto social", mas também reconhecer que as desigualdades sociais resultam em profundos impactos na saúde da população. Nesse sentido, há a 
importância de uma perspectiva ampliada sobre as condições sociais responsáveis pela produção de saúde e/ou processos de adoecimento - lembrando que a exclusão social mata. Não por acaso, no campo da saúde coletiva, os determinantes sociais em saúde são definidos como "fatores sociais, econômicos, culturais, étnicos/raciais, psicológicos e comportamentais que influenciam a ocorrência de problemas de saúde e seus fatores de risco na população" (Buss \& Pellegrini Filho, 2006, p. 2005).

Em nosso entender, isso resulta no terceiro pressuposto: o do impacto dos marcadores sociais de diferença nas políticas de saúde à medida que atravessam práticas, serviços e respostas. Numa perspectiva interseccional, o desafio consiste em não perder de vista "como diferentes eixos de subordinação se articulam em um mesmo sujeito social, fazendo com que as lógicas de exclusão/aceitação que os atingem sejam potencialmente distintas, a depender do contexto social em que se encontrem" (Mello et al., 2011, p. 13). Portanto, tratase de reconhecer que, no caso específico da população LGBTQIA+, “[...] o sujeito não pode ser pensado apenas como 'gay', 'lésbica', 'bissexual', 'travesti' ou 'transexual', já que seu corpo/self também pode ser negro-rico-jovem, entre tantas Rev. Polis e Psique, 2021; 11(3): 81 - 99 outras combinações possíveis dos atributos raça/cor, classe social e idade" (Mello et al., 2011, p. 13).

\section{Uma "ausência" diz mais do que mil palavras}

Entre os dias 11 e 12 de abril de 2019, no auditório de uma universidade privada da cidade de Dourados - MS, ocorreu a $8^{a}$ Conferência Municipal de Saúde (CMS). O evento fez parte das atividades preparatórias para a $9^{\text {a }}$ Conferência Estadual de Saúde, realizada nos dias 4 e 5 de junho de 2019 em Campo Grande, e para a $16^{\mathrm{a}}$ Conferência Nacional de Saúde, realizada de 4 a 7 de agosto de 2019 em Brasília.

A CMS contou com um grande número de participantes (620), superando as expectativas iniciais (em torno de, no máximo, 400 pessoas). Ao longo de seu desenvolvimento, houve intensa participação dos/as trabalhadores/as da rede, gestores/as, usuários/as e estudantes universitários/as de diferentes áreas disciplinares.

As discussões, sempre muito acaloradas, mostraram certo desconhecimento por parte de alguns dos participantes - em geral trabalhadores da rede - dos princípios e das diretrizes do 
SUS. Assim, se entre os princípios do SUS a equidade preconiza que "todo cidadão é igual perante o SUS e será atendido conforme suas necessidades" (Brasil, 1990a, p. 5), o que se observou foi que a demanda por inclusão por parte de segmentos sociais minoritários era compreendida ora como "privilégio de uns em detrimento de outros" (no caso de população indígena e negra), ora como uma pauta menos importante se comparada "a necessidades mais graves e urgentes" e da "maioria".

Assim, se ao longo da Conferência foi possível observar algumas conquistas quanto ao reconhecimento de demandas apresentadas pela população indígena e negra do município de Dourados e macrorregião, o mesmo não pode ser dito em relação à população LGBTQIA+. Além de permanecer bastante invisível ao longo dos dois dias de trabalho, sendo mencionada apenas uma única vez, por um professor universitário que ali participava como usuário e que se referiu especificamente à saúde da população trans, tal invisibilidade foi reiterada ao final quanto às propostas aprovadas pelo plenário e encaminhadas para a Conferência de nível estadual. Tais imbróglios falam de uma série de desafios que precisam ser superados para a conquista e efetivação dos direitos sexuais de minorias no contexto da saúde pública no País e, ao mesmo tempo, revelam a permanência de vários entraves políticosociais-simbólicos que reiteram uma condição de subcidadania por parte desses segmentos.

Não por acaso, em pesquisa recente realizada por Filipiack e Gaspodin (2019), voltada para a compreensão das principais políticas públicas para a população LGBTQIA+ no Brasil, constata-se que os principais entraves estão justamente no campo da saúde e que um dos grandes obstáculos se refere ao preconceito e ao despreparo de profissionais para lidar com as especificidades das demandas desses grupos.

\section{Dilemas da população LGBTQIA+ no campo da saúde: um pequeno balanço}

Mello et al. (2011), ao analisarem as políticas públicas de saúde voltadas à população LGBTQIA+ no Brasil, apontam que, embora haja uma série de conquistas nas últimas décadas no que diz respeito a dispositivos legais, há muito o que se fazer com relação a acessos e efetividades.

Para os autores, o ano de 2004 foi um marco no que tange ao engajamento do governo brasileiro na promoção da 
cidadania desses grupos, por meio do Programa Brasil Sem Homofobia, que trazia em seu escopo a proposta de atuar em diferentes frentes, dentre elas a saúde da população LGBTQIA+. Dentre suas principais repercussões, destacam-se a Política Nacional de Atenção Integral à Saúde da Mulher: Princípios e Diretrizes (2004), a Carta dos Direitos dos Usuários da Saúde (2006), o Plano Integrado de Enfrentamento da Feminização da Epidemia de Aids e outras DST e o Plano Nacional de Enfrentamento da Epidemia de Aids e DST entre Gays, outros Homens que fazem Sexo com Homens e Travestis (2007), o Plano Nacional de Promoção da Cidadania e Direitos Humanos de Lésbicas, Gays, Bissexuais, Travestis e Transexuais (2009), o III Programa Nacional de Direitos Humanos (PNDH 3) (2009) e a Política Nacional de Saúde Integral da População LGBTQIA+ (2011) (Mello et al., 2011).

Apesar dessas conquistas, constatase que se “[...] ainda há problemas estruturais que precisam ser superados se pretendemos assegurar universalmente serviços de saúde de qualidade para a população brasileira" (Mello et al., 2011, p. 11); quando se leva em consideração a população LGBTQIA+, os desafios e dilemas são ainda muito maiores. Isso é Rev. Polis e Psique, 2021; 11(3): 81 - 99 concretamente observável quando passamos de uma análise macro para uma análise micro, ou seja, quando buscamos deslindar as políticas específicas para cada segmento na ponta dos serviços. Lembrando que a entrada no Sistema se dá nas Unidades Básicas de Saúde e que é justamente ali que há a maior incidência de desrespeito aos direitos dessa população. São inúmeras as pesquisas que revelam o descumprimento em relação ao tratamento pelo nome social de travestis e transexuais, a violência a que são submetidas mulheres lésbicas por parte de alguns ginecologistas, a falta de um atendimento específico voltado para homens trans, dentre outras situações.

No âmbito das políticas voltadas para a população lésbica, o grande marco é a Política Nacional de Atenção Integral à Saúde da Mulher (2004). No seu cerne está o reconhecimento das especificidades que cercam a saúde da mulher. Apesar disso, há a constatação, por parte de diferentes pesquisadoras, de que estamos longe de uma atenção diferenciada quando o assunto é população lésbica. De acordo com Facchini e Barbosa (2006),

A escassa, ou quase inexistente, produção científica abordando a temática saúde e homossexualidade 
feminina no Brasil; a inexistência de políticas de saúde consistentes para o enfrentamento das dificuldades e necessidades desta população; $\quad$ o $\quad$ precário conhecimento sobre suas demandas e a ausência de tecnologias de cuidado à saúde adequadas, aliados à persistência de pré-noções e preconceitos, convertem-se, no âmbito da saúde pública, por exemplo, no desperdício de recursos, no constrangimento produzido no atrito das relações no interior dos serviços de saúde, na assistência inadequada, e muito provavelmente num contingente de mulheres que não obtiveram seu diagnóstico, nem seu tratamento (Facchini \& Barbosa, 2006, p. 29).

No que tange à política voltada para a população trans, diferentes pesquisadores e pesquisadoras apontam para o que chamam de uma complexa e redutora hegemonia de um "dispositivo da transexualidade" (Bento, 2006; Borba, 2016). Nele, masculinidades e feminilidades trans são reduzidas aos ditames de um binarismo de gênero e o requisito fundamental para o acesso aos serviços de saúde ainda é a psicopatologização das identidades trans. Assim, se de um lado há uma conquista quanto ao direito de acesso ao processo transexualizador no interior do SUS, de outro há a prevalência de um dispositivo disciplinador e patologizador dessas identidades (Rocon, Sodré \& Rodrigues, 2016; Lionço, 2009).

Além disso, e como um de seus efeitos, há o consequente apagamento de uma série de experiências em torno das transexualidades que não se reduzem às cirurgias de redesignação sexual. Em trabalho recente junto a transexuais masculinos, Braz e Souza (2018) chamam a atenção para o fato de que, apesar da experiência identitária plural da transexualidade, as políticas de saúde continuam centradas na transexualidade feminina. Para os autores, é preciso pensar e produzir políticas de saúde transespecíficas.

Tal enquadramento biomedicalizador e restritivo, não pode ser desvinculado de uma lógica de patologização das pessoas trans. Com relação a isso, Nascimento problematiza “o quanto os padrões normativos de gênero utilizados pelos profissionais psi no diagnóstico das subjetividades trans é limitante e colonizador" (Nascimento, 2021, p. 113). 


\section{A crise da Covid-19 e a produção de novos dilemas}

Dados recentes revelam que, se as condições de saúde no Brasil têm piorado nas últimas décadas, incidindo diretamente sobre as condições de vida da população, no contexto pandêmico por nós vivenciado as consequências sociais tendem a ser ainda mais graves para os sujeitos e coletivos historicamente vulnerabilizados. Ainda assim, essa incidência não atinge todos da mesma maneira (Oliveira et al., 2020). É isso o que têm demonstrado os dados produzidos por organizações governamentais e não governamentais, instituições de pesquisa, associações científicas, pesquisadores e pesquisadoras em balanços recentes sobre os impactos da pandemia no País. Na linha de frente do morticínio, mulheres negras e indígenas, LGBTQIA+, população de rua, população em privação de liberdade. Em todos esses segmentos, marcadores comuns, como gênero, orientação sexual, classe e raça.

Barroso e Gama (2020, p. 86) são taxativas ao afirmarem: a crise da Covid19 tem rosto. E que rosto é esse? Um rosto feminino marcado por raça e classe. Nas palavras das autoras, "desigualdades de gênero, bem como de raça, território, regionalidade, renda e escolaridade, são as responsáveis por colocar mulheres pobres no centro dos grupos possivelmente mais afetados pela pandemia do coronavírus". A partir de dados produzidos pelo IPEA, IBGE, Dieese, CEBRAP, Instituto Data Favela, Cufa e Instituto Locomotiva, dentre outras organizações governamentais e não governamentais, Barroso e Gama apontam que, se historicamente há uma feminização da pobreza no Brasil, "as desigualdades de gênero particularizam os impactos da crise do Coronavírus" (2020, p. 92). Em cena, vulnerabilidades econômicas, divisão desigual de tarefas domésticas e sobrecarga de trabalho doméstico não remunerado, crescimento da violência doméstica e intrafamiliar e ataque aos direitos sexuais e reprodutivos.

Ainda em relação ao recorte etnicorracial e de gênero, de acordo com a Comissão Econômica para a América Latina e o Caribe (Cepal), em relatório divulgado em 12 de maio de 2020, mulheres negras e indígenas estarão entre os grupos mais afetados pelo impacto socioeconômico do coronavírus na América Latina ${ }^{2}$.

Em nota de 21 de abril de 2020, a Associação Brasileira de Saúde Coletiva (ABRASCO) lançava um alerta sobre os riscos de intensificação do preconceito e da 
violência contra a população LGBTQIA+. De acordo com a Associação, o cenário instaurado pela epidemia de Covid-19 pode contribuir com a "agudização de disparidades e iniquidades já existentes"3.

Pesquisa realizada pelo coletivo VOTELGBTQIA+ (2020) junto a 9.521 pessoas apontou que, no contexto da pandemia, uma em cada cinco pessoas LGBTQIA+ não possui nenhuma fonte de renda individual ${ }^{4}$. Certamente esses índices tendem a ser ainda mais graves quando se consideram homossexuais, bissexuais e travestis, já que para muitos deles e delas a prostituição se coloca como a principal fonte de renda - em alguns casos, a única.

Do mesmo modo, em informativo recente, a ONG australiana Rainbow Health Victoria $^{5}$ afirmava três aspectos de maior vulnerabilidade em relação aos impactos da pandemia para os/as LGBTQIA+: saúde mental, violência familiar e desigualdade social. Por sua vez, a Associação Internacional de Lésbicas, Gays, Bissexuais, Transexuais e Intersexuais para a América Latina e o Caribe (ILGA) ${ }^{6}$ também endossa esse cenário no contexto pandêmico em face dos contínuos processos de violência, discriminação e estigmatização a que estão historicamente submetidos.
No âmbito específico da vida universitária, Oliveira et al. (2020) também chamam a atenção para o impacto da pandemia nas redes de afeto e apoio de LGBTQIA+ como consequência da suspensão das atividades presenciais nas Universidades brasileiras. De acordo com os pesquisadores,

Mães estudantes que passaram a conviver em tempo integral com seus/as filhos/as pequenos/as cumprindo medidas de isolamento social em casa devido ao fechamento das creches, têm relatado dificuldades em estudar, assim como jovens homossexuais que, devido sua sexualidade, carecem de apoio dos/as familiares e encontram-se desassistidos em relação a uma rede de acolhida, bem como de um ambiente universitário apropriado que os favoreçam na dedicação aos estudos (Oliveira et al., 2020, p. 69).

As diferentes pesquisas chamam a atenção para o fato de que governos e sociedade civil precisam estar atentos às populações e grupos socialmente vulneráveis, a fim de que sejam evitados 
e/ou minorados os processos de vulnerabilidade a que estão cotidianamente submetidas minorias sexuais e de gênero, e cujo contexto pandêmico tende a agravar ainda mais.

Em meio à crise sanitária, nos interrogamos como a população LGBTI (Lésbicas, Gays, Bissexuais, Transexuais, Travestis e Intersexuais), está vivenciando a pandemia da COVID-19, considerando os rebatimentos particulares nesse público. [...]. A impossibilidade de acesso a saúde, educação, habitação e políticas de emprego e renda vinculam-se à invisibilidade e exclusão de determinados indivíduos, cujos indicadores sociais sequer são mapeados por parte do poder público, dificultando as iniciativas e ações de enfrentamento à discriminação. Além da subnotificação dos dados, em geral, sistematizados pelas organizações LGBTI, atravessamos uma onda negacionista e persecutória que descredibiliza as pesquisas científicas produzidas no âmbito das universidades e dos institutos de pesquisa. (Lacerda, 2020, s/p).

Assim, o perigo é que ações de caráter sanitário exigidos pela gravidade do momento tendam a obscurecer demandas específicas em nome das justificativas de "urgência" e/ou de "maioria". Nesse enquadre de violências sistêmicas que passam a ser relativizadas em nome de um "estado de emergência de saúde pública”, recuperar as diretrizes preconizadas e garantidas pelo SUS é fundamental. Trata-se de reafirmar a necessidade de uma política de saúde equitativa, em que "temos o direito a ser iguais quando a nossa diferença nos inferioriza; e temos o direito a ser diferentes quando a nossa igualdade nos descaracteriza. Daí a necessidade de uma igualdade que reconheça as diferenças e de uma diferença que não produza, alimente ou reproduza as desigualdades" (Santos, 2003, p. 56). Afinal, uma perspectiva de equidade

pressupõe que a universalidade dos direitos humanos e sociais só pode ser assegurada mediante $\mathrm{o}$ reconhecimento e consideração das diferenças entre grupos sociais que se encontram em situação não apenas de distinção, mas também de desigualdade. Uma democracia 
liberal tem a equidade como princípio de justiça, por meio do reconhecimento de que as diferenças sociais, econômicas e morais não deveriam idealmente comprometer a garantia dos direitos, que são universais e aos quais não caberiam exclusões, mas que requerem estratégias diferenciadas para a garantia dos direitos em situações e circunstâncias distintas (Lionço, 2009, p. 46).

\section{Algumas (in)conclusões políticas}

Melo e Barreto (2014) situam a Psicologia como um campo de conhecimento recente e em cujas origens esteve vinculado ao racionalismo cartesiano. Enquanto buscava afirmar-se como um saber fora de qualquer suspeita, portanto, enquanto "ciência" psicológica, a Psicologia "permitiu a construção de saberes sobre o homem fortemente vinculado às dicotomias saúde/doença, indivíduo/sociedade, à identificação psicodiagnóstica e cura das ditas anormalidades" (Melo \& Barreto, 2014, p. 677-678). A partir de entrevistas realizadas com acadêmicos e acadêmicas calouros/as e veteranos/as de cursos de Psicologia de uma universidade pública e outra privada, os autores constatam que, quando o assunto é gênero, diversidade sexual e sexualidades dissidentes, por vezes ainda prevalece um modelo binário e hegemônico.

Lenise Borges et al. (2013), por sua vez, a partir de um levantamento bibliográfico da produção do curso de graduação e pós-graduação da Universidade Católica de Goiás (PUCGoiás) sobre gênero e sexualidade, apontam como o saber psicológico está vinculado a uma "(re)produção de saber" que muitas vezes é reiterativo de moralidades e normalizações. Não por acaso isso resulta numa visão normativa, polarizada e patologizada quanto ao gênero e às sexualidades.

Modesto (2020), debruçando-se sobre as discussões de gênero no interior da Psicologia, aponta para a importância da superação de uma perspectiva centrada no indivíduo e da necessidade de se privilegiar questões sociais mais amplas. Nas palavras da autora,

Possivelmente, por razões fortemente atreladas à ideia de uma psicologia centrada no indivíduo e sua ampla difusão em cursos de formação de psicólogas, o conceito 
de gênero por inúmeras vezes acaba circunscrito, na prática e pesquisa psicológicas, a características individuais, à esfera da família e à experiência doméstica e é pouco utilizado para compreender outros sistemas: sociais, políticos, econômicos ou de poder, estratégia fundamental para a ampla apreensão contextual de fenômenos com os quais lida esta profissional. Para compreender as complexas demandas que a sociedade apresenta é necessário transpor a ideia de uma psicologia centrada no indivíduo e complexificar a análise das relações sociais (Modesto, 2020, p. 14-15).

Refletindo sobre os desafios que cercam a inclusão da pauta LGBTQIA+ na formação de psicólogos/as, Graciani (2020), citando o código de ética da profissão, a Resolução n. $1 / 1999^{7}$ e a Resolução n. $01 / 2018^{8}$, reitera o compromisso do Conselho Federal de Psicologia com a pauta dos direitos humanos e seu engajamento com uma prática profissional pautada no "compromisso social de combate à discriminação, fomento de uma cultura inclusiva, participativa e respeitosa" (Graciani, 2020, p. 76).

Ao iniciar essa reflexão a partir de uma experiência junto a uma Conferência Municipal de Saúde, desejamos não apenas ilustrar as contradições que cercam as discussões sobre saúde atualmente, mas principalmente apontar algumas complexidades que atravessam a noção de equidade quando a pauta é minorias sexuais e de gênero, buscando pensar também o lugar da Psicologia nesse debate. A partir de um enquadre crítico e desnaturalizador ao qual nos vinculamos, não basta uma ampliação da noção de saúde (tal como a preconizada pela OMS em 1948). Afinal, em contextos tão marcados por desigualdades como o Brasil, é fundamental que não nos furtemos a perguntar sobre o exato sentido de "bemestar", de "bem viver" (Carvajal, 2020).

Nesse sentido, é preciso que reafirmemos os limites de uma visão de saúde e de uma prática de/em saúde (e também psicológica) desvinculada das relações de poder que as enredam. Uma perspectiva asséptica, seja de saúde, seja de "ciência" psicológica, pode contribuir não apenas para o não enfrentamento dos processos de invisibilização, hierarquização e desigualdade, mas também para sua reiteração. Não por 
acaso, em trabalho recente, Oliveira e Duque (2021) problematizam o quanto a Psicologia hegemônica ainda é atravessada por dispositivos disciplinares e moralizadores. Ao privilegiar o indivíduo em detrimento do contexto, ao privilegiar um sujeito "normal" sem problematizar o papel dos regimes que produzem a norma, ao desconsiderar a dimensão política de sua prática e suas repercussões sociais e (inter)subjetivas, a Psicologia perde seu caráter crítico e se institui como ferramenta capitalística para fins da normatização e controle das vidas (Silva, 2009).

"Diga-me que práxis de/em saúde fazes e te direi quem és." Uma Psicologia que não esteja atenta às localizações e datações de suas noções e categorias (que orientam sua prática) e às relações de saber-poder que a atravessam, às dinâmicas específicas de sujeitos e grupos e suas relações, a outras noções de identidade e autonomia, aos mecanismos sociais de exclusão que precarizam a vida de sujeitos e coletivos e suas condições de existência, à dimensão político-econômicoideológica que dão contorno às suas intervenções, corre o risco de se constituir como uma prática nefasta.

Com relação ao segundo ponto, vale ressaltar que não são meros acasos os dados apresentados ao longo do texto em relação aos impactos da pandemia sobre minorias sexuais e de gênero. Numa sociedade cujo modelo continua a ser o cis-heteronormativo, patriarcal, racista, classista, mulheres e LGBTQIA+ são alvos fáceis do abandono do Estado. Esse abandono se releva concretamente na precariedade das políticas públicas, senão no interior dos documentos oficiais (normativas e diretrizes), principalmente na ponta do serviço. É ali nos "postinhos de saúde" (como falam usuários e usuárias) ou nas UPAs (Unidades de Pronto Atendimento) que corpos generificados, transviados e dissidentes travam uma luta cotidiana para que sua cidadania seja reconhecida e respeitada. Nesse embate pela superação da condição de subcidadania, corpos marcados por gênero, identidade de gênero, orientação sexual, classe e raça (dentre outros) manifestam seus desejos por concepções e práticas ampliadas de saúde.

Há que se ponderar sobre os elementos simbólicos e políticos que atravessam discursos e práticas em torno da tão propagada "equidade". Ela está longe de ser consensual e socialmente assumida e compartilhada. Numa sociedade em que direitos diferenciados ainda são compreendidos na chave dos "privilégios" e/ou do perigo ("perigo" de 
que a conquista de direito de um segmento seja interpretada como perda de direito para outro); em que determinadas vidas parecem valer mais do que outras (Butler, 2015); em que cidadania parece não ser direito de todo cidadão e cidadã, mas condição a ser acessada segundo critérios moralizantes e excludentes - vide travestis e transexuais (Becker \& Oliveira, 2016) -, a saúde precisa ser compreendida para além dos ditames psicobiomedicalizantes. É preciso reafirmar o princípio fundamental da constituição cidadã, de saúde como direito de todos e todas. Em tempos de necropolítica, como o que temos vivido no Brasil, é preciso desvelar os privilégios, os racismos, os sexismos, as LGBTQIA+fobias. É preciso denunciá-los, desnaturalizá-los, confrontá-los. E gritar incessantemente: Nossas vidas importam!

Por fim, neste momento em que fazemos memória de mais de 581 mil mortos (até o fechamento deste texto), inúmeros anônimos e anônimas, em que vivenciamos constantes ataques ao SUS e aos seus profissionais, em que experimentamos as violências simbólicas do discurso negacionista, mais do que nunca somos desafiados a lutar pela criação coletiva de zonas de fuga, a buscar a superação das políticas de cancelamento, a construir políticas de vida e de saúde ampliadas, interseccionais e em aliança. Afinal,

Sem dúvida, entre nós existem diferenças bem reais de raça, idade e gênero. Mas não são elas que estão nos separando e sim nossa recusa em reconhecer essas diferenças e em examinar as distorções que resultam do fato de nomeá-las de forma incorreta e aos seus efeitos sobre o comportamento e a experiência humana. Racismo, a crença na superioridade inata de uma raça sobre todas as outras e, assim, o direito à predominância. Sexismo, a crença na superioridade inata de um sexo sobre o outro e, assim, o direito à predominância. Discriminação etária. Heterossexismo. Elitismo. Classismo. (Lorde, 2019, p. 240).

Talvez, a partir daí compreendamos finalmente a potência do princípio de equidade e consigamos produzir narrativas e práticas contra-hegemônicas, visando uma Psicologia mais inclusiva e menos normativa.

\section{Notas}


${ }^{1}$ De acordo com o artigo $3^{\circ}$ da Lei n. 8.080 de 1990, "a saúde tem como fatores determinantes e condicionantes, entre outros, a alimentação, a moradia, o saneamento básico, o meio ambiente, o trabalho, a renda, a educação, o transporte, o lazer e o acesso aos bens e serviços essenciais; os níveis de saúde da população expressam a organização social e econômica do País" (Brasil, 1990b).

2

Fonte:

https://g1.globo.com/mundo/noticia/2020/05/1 2/mulheres-e-indigenas-estao-entre-os-maissocialmente-afetados-pela-covid-19-naamerica-latina-diz-relatorio.ghtml.

3 Disponível em: https://www.arca.fiocruz.br/bitstream/icict/413 75/2/Impactos Sociais.PDF.

4 Disponível em:

https://www.voteLGBTQIA+.org/pesquisas.

5 Disponível em:

https://rainbowhealthvic.org.au/media/pages/re search-resources/research-briefing-papercovid-19-impacts-for-LGBTQIA+iq-

communities-and-implications-forservices/817379592-1586396368/rainbow-

health-victoria-research-briefing-paper-covid-

19.pdf.

${ }^{6}$ Disponível em:

https://www.ilga-

europe.org/sites/default/files/COVID19\%20_I

mpact\%20LGBTQIA+I\%20people.pdf.

7 Resolução que estabelece as normas para atuação dos psicólogos frente às demandas da orientação sexual.

${ }^{8}$ Resolução que garante o uso do nome social por parte dos profissionais da Psicologia em sua identificação profissional.

\section{Referências}

Barata, R. B. A. (2009). Posição social e seus reflexos sobre a saúde. In Como e por que as desigualdades sociais fazem mal à saúde [online] (p. 23-39)
Rio de Janeiro, Brasil: Editora Fiocruz. Recuperado de http://books.scielo.org/id/48z26/pdf/ba rata-9788575413913-03.pdf.

Barroso, H. C., \& Gama, M. S. B. (2020). A crise tem rosto de mulher: como as desigualdades de gênero particularizam os efeitos da pandemia da COVID-19 para as mulheres no Brasil. Revista do Ceam, Brasília, 6(1), 84-94. doi: https://doi.org/10.5281/zenodo.395330 $\underline{0}$.

Bento, B. A. (2006). (Rre)Iinvenção do corpo: sexualidade e gênero na experiência transexual. Rio de Janeiro, Brasil: Garamond.

Becker, S., \& Oliveira, E. A. (2016). Educação e Direitos para (in) Humanos? Desafios e Reflexões sobre os Dilemas de LGBT's perante o Discurso Jurídico Brasileiro. Revista Tempos e Espaços em Educação, 9, 163-179. doi: https://doi.org/10.20952/revtee.v9i19. $\underline{5603}$

Borba, R. (2016). O (des)aprendizado de si: transexualidades, interação $e$ cuidado em saúde. Rio de Janeiro, Brasil: Fiocruz.

Borges, L. S., Canuto, A. A. A., Oliveira, D. P., \& Vaz, R. P. (2013). Abordagens de gênero e sexualidade na Psicologia: revendo conceitos, repensando práticas. Psicol. cienc. prof., 33(3), 730-745. doi: https://doi.org/10.1590/S1414$\underline{98932013000300016}$

Butler, J. (2015). Quadros de guerra: quando a vida é passível de luto? Rio de Janeiro, Brasil: Civilização Brasileira. 
Brasil (1990a). ABC do SUS: doutrina e princípios. Brasília: Ministério da Saúde.

Brasil (1990b). Lei $\mathrm{n}^{\circ}$ 8.080, de 19 de setembro de 1990. In Legislação do SUS. Brasília: CONASS, 2003. Recuperado de http://bvsms.saude.gov.br/bvs/publica coes/progestores/leg_sus.pdf.

Braz, C., \& Souza, E. R. (2018). Transmasculinidades, transformações corporais e saúde: algumas reflexões antropológicas. In Caetano, M., \& Silva Junior, P. M. (2018). De guri a cabra-macho: masculinidades no Brasil (p. 28-42). Rio de Janeiro, Brasil: Lamparina.

Buss, P. M., \& Pellegrini Filho, A. (2006). Iniquidades em saúde no Brasil, nossa mais grave doença: comentários sobre o documento de referência e os trabalhos da Comissão Nacional sobre Determinantes Sociais da Saúde. Cadernos de Saúde Pública, 22(9), 2005-2008. doi:

https://doi.org/10.1590/S0102$\underline{311 X 2006000900033}$

Carvajal, J. P. (2020). Uma ruptura epistemológica com o feminismo ocidental. In Hollanda, H. B. (Org.). Pensamento Feminista Hoje: Perspectivas Decoloniais (194-204). Rio de Janeiro, Brasil: Bazar do Tempo.

Duarte, L. F. D. (1988). Da vida nervosa nas classes trabalhadoras urbanas $(2 \mathrm{a}$ ed.). Rio de Janeiro, Brasil: Zahar.

Facchini, R., \& Barbosa, R. M. (2006). Dossiê: Saúde das Mulheres Lésbicas promoção da equidade $e \quad d a$ integralidade. Belo Horizonte, Brasil:
Rede Feminista de Saúde. Recuperado de

http://www.cfess.org.br/arquivos/dossi e_da_saude_da_mulher_lesbica.pdf.

Ferreira, A. B. H. (2001). Miniaurélio (4a ed.). Rio de Janeiro, Brasil: Nova Fronteira.

Filipiack, I. C., \& Gaspodini, I. C. (2019). Políticas Públicas para a população LGBT no Brasil. Perspectivas em Psicologia, 23(2), 40-56. Recuperado de

http://www.seer.ufu.br/index.php/pers pectivasempsicologia/article/view/522 $\underline{11 .}$

Graciani, J. S. (2020). Desafios na formação de psicólogos diante da inclusão da população LGBTQIA+QIA+. In Almeida, D. M., Silva, D. G. S., \& Silva, J. R. S. Sequências didáticas sobre gênero $e$ diversidade (71-90). São Paulo, Brasil: Editora na Raiz.

Lacerda, M. C. (2020). "Entre a deriva e o naufrágio": notas sobre a população LGBTI em tempos de pandemia da COVID-19. In Lole, A., Stampa, I., \& Gomes, R. L. R. (Orgs.). Para além da quarentena: Reflexões sobre crise $e$ pandemia. Rio de Janeiro, Brasil: Mórula Editorial.

Lionço, T. (2009). Atenção integral à saúde e diversidade sexual no Processo Transexualizador do SUS. Physis, Rio de Janeiro, 19(1), 43-63. doi: $\quad$ https://doi.org/10.1590/S010373312009000100004 .

Lorde, A. (2019). Idade, raça, classe e gênero: mulheres redefinindo a diferença. In Hollanda, H. B. (2019). Pensamento feminista: conceitos 
fundamentais (239-249). Rio de Janeiro, Brasil: Bazar do Tempo.

Melo, R. A. \& Barreto, D. J. (2014). Formação em Psicologia: Discursos e Saberes sobre Experimentações de Gênero. Psicol. cienc. prof., 34(3), 676-689. doi: https://doi.org/10.1590/19823703000932012 .

Mello, L., Perilo, M., Braz, C. A., \& Pedrosa, C. (2011). Políticas de saúde para lésbicas, gays, bissexuais, travestis e transexuais no Brasil: em busca de universalidade, integralidade e equidade. Sexualidad, Salud y Sociedad - Revista Latinoamericana, (9), 7-28. doi: https://doi.org/10.1590/S1984$\underline{64872011000400002}$.

Modesto, A. E. (2020). Discutindo dimensões do gênero com estudantes de psicologia. In Almeida, D. M., Silva, D. G. S., \& Silva, J. R. S. (2020). Sequências didáticas sobre gênero e diversidade (12-26). São Paulo, Brasil: Editora na Raiz. Recuperado de https://zenodo.org/record/4254204\#.X 9oHSflKiM8.

Nascimento, L. (2021). Transfeminismos. Coleção Feminismos Plurais. São Paulo, Brasil: Jandaíra.

Oliveira, E. A., \& Duque, T. (2021). Algumas reflexões indisciplinadas sobre diversidade, diferença e inclusão. In Almeida, D. M. M., Zanon, R. B., Feitosa, L. R. C., \& Anache, A. A. (Orgs.). Psicologia, educação e trabalho: inclusão em diferentes contextos (109-118). Curitiba, Brasil: CRV.
Oliveira, E. A., Passamani, G. R., Rosa, M. V., \& Duque, T. (2020). "Salve-se quem puder": dilemas de estudantes das universidades federais do Mato Grosso do Sul em tempo de pandemia. Cadernos de Campo, 29(supl.), 65-74. doi:

https://doi.org/10.11606/issn.23169133.v29isuplp65-74

Rocon, P. C., Sodré, F., \& Rodrigues, A. (2016). Regulamentação da vida no processo transexualizador brasileiro: uma análise sobre a política pública. Revista Katálysis, 19(2), 260-269. doi: https://doi.org/10.1590/141449802016.00200011.

Santos, B. S. (2003). Reconhecer para libertar: os caminhos do cosmopolitismo multicultural. Rio de Janeiro, Brasil: Civilização Brasileira.

Schwarcz, L. K. M. (2019). Prefácio. In Hirano, L. F. K., Acuña, M., \& Machado, B. F. (Orgs.). Marcadores sociais das diferenças: fluxos, trânsitos e intersecções (8-19). Goiânia, Brasil: Imprensa Universitária.

Silva, T. T. da (Org.) (2009). Identidade e diferença: a perspectiva dos estudos culturais. Petrópolis, Brasil: Vozes.

Silveira, M. L. (2000). O nervo cala, o nervo fala: a linguagem da doença. Rio de Janeiro, Brasil: Fiocruz.

Esmael Alves de Oliveira é professor adjunto do curso de Ciências Sociais, do Programa de Pós-Graduação em Antropologia (PPGAnt) e do Programa de Pós-Graduação em Psicologia (PPGPsi) da Faculdade de Ciências Humanas da 
Universidade Federal da Grande Dourados

Submissão: 16/12/2020

(FCH/UFGD).

E-mail: esmael_oliveira@live.com

$1^{\circ}$ avaliação: $22 / 02 / 2021$

ORCID: http://orcid.org/0000-0002-9235-

$\underline{5938}$

$2^{\circ}$ avaliação: 06/09/2021

Aceite: $17 / 10 / 2021$ 